\title{
URBANIZAÇÃO BRASILEIRA \\ Um Olhar Sobre o Papel das Cidades Médias na Primeira Década do Século XXI
}

\author{
Angela Moulin S. Penalva Santos
}

R E S U M O O objetivo deste artigo é refletir sobre o papel das cidades com população superior a 100 mil habitantes na rede urbana brasileira na primeira década do século XXI. Partimos da premissa de que está em curso uma tendência de urbanização com concentração da população em um número reduzido de cidades, em um contexto de perda de centralidade da Induistria. Nesse processo, afirmam-se as metrópoles, mas aumenta a relevância de um grupo de cidades de médio porte, algumas das quais se tornaram centros regionais e articuladoras do território. Estamos chamando esse grupo de "cidades médias não metropolitanas" as cidades com população superior a 100 mil habitantes que não sejam capitais estaduais ou localizadas em regiōes metropolitanas. A urbanização crescente com maior polarização espacial tem sido alimentada pela maior geração de empregos naquelas cidades, o que torna necessário que sejam implementadas politicas públicas que visem mitigar os efeitos da crise urbana que as metrópoles já experimentam.

P A L A V R A S - C H A V E Cidades médias; urbanização; polarização espacial; geração de empregos; rede urbana.

\section{INTRODUÇÃO}

O objetivo deste artigo é refletir sobre o papel das cidades com população superior a 100 mil habitantes na rede urbana brasileira na primeira década do século XXI. Apesar de ser um pequeno número de municípios, participam com elevado percentual da população e das atividades econômicas do País, além de experimentarem fortes pressões que poderão levar aos já conhecidos efeitos da crise socioambiental vivenciada pelas metrópoles.

Partimos da premissa de que está em curso uma tendência de urbanização com grande volume da população em um número reduzido de cidades, em um contexto de perda de centralidade da indústria. Nesse processo, afirmam-se as metrópoles, mas aumenta a relevância de um grupo de cidades de médio porte na rede urbana, algumas das quais se tornaram centros regionais e articuladores do território. Estamos chamando esse grupo de "cidades médias não metropolitanas" - cidades com população superior a 100 mil habitantes que não sejam capitais estaduais ou localizadas em regiōes metropolitanas.

O trabalho está organizado em três seções. Na primeira, apresentamos dados sobre a situação da população mundial para sugerir que está em curso um processo de intensificação da urbanização e concentração da população em poucas cidades. Esse é o resultado da expectativa suscitada pela teoria urbanística que indica a perda de centralidade da Indústria em favor dos Serviços como setor gerador de empregos. Nessas condições, são as grandes cidades que reúnem infraestrutura mais adequada à dinâmica econômica globalizada. O crescimento urbano, no entanto, vem transbordando para cidades médias, 
que passam a apresentar o meio técnico disponível nas áreas metropolitanas, ainda que em escala reduzida.

$\mathrm{Na}$ segunda seção, observamos a evidência empírica, analisando alguns indicadores construídos a partir do Censo 2000 e do Cadastro Geral de Empregos do Ministério do Trabalho. O objetivo é situar os 252 municípios brasileiros com mais de 100 mil habitantes, analisando se há base empírica para que cumpram o papel que a teoria urbanística sugere. Os indicadores sociais municipais proporcionam um retrato desses municípios no início da década, enquanto os dados de empregos permitem avaliar seu desempenho ao longo da primeira década do século XXI. Em uma primeira subseção, analisamos dois indicadores sociais municipais: a renda média dos responsáveis pelos domicílios e o grau de vulnerabilidade dos residentes nos municípios brasileiros. Esses dados permitem identificar duas dimensões da importância desse grupo de municípios na rede urbana: o valor do rendimento dos trabalhadores e alguns elementos que possibilitam inferir as condições de vida de seus residentes. Na segunda subseção observamos a evolução de outro indicador da atração exercida por aqueles municípios: os empregos gerados ao longo da primeira década do século XXI. Utilizamos esse indicador por existirem informações atualizadas e por refletirem melhor o dinamismo econômico que impacta positivamente as condições de vida da população local do que a evolução do Produto Interno Bruto (PIB). Em ambos os casos, buscamos evidências de que os municípios de maior porte populacional oferecem maiores oportunidades de emprego, o que explicaria sua importância crescente na rede urbana brasileira, destacando sempre o papel das cidades médias.

$\mathrm{Na}$ terceira e última seção, apresentamos as conclusóes do estudo.

\section{UMA REDE URBANA MENOS EQUILIBRADA}

\section{InTENSIFICAÇÃo da URbanizaçÃo COM CONCENTRAÇÃo da PopUlaÇÃo nas Grandes Cidades}

O grau de urbanização da população mundial em 2005 atingiu 48,6\%, mas, segundo estudo da Organização das Nações Unidas (ONU) de 2007, esse percentual atingirá $50,6 \%$ no ano de 2010. Enquanto a população rural cresce a uma taxa anual de $0,37 \%$, a população urbana evolui a uma taxa muito maior, de 1,98\%, anual (ONU, 2007).

Segundo o mencionado estudo, o aumento da urbanização da população será acompanhado de crescente concentração da população em cidades de maior porte populacional: em 2005, existiam 18 cidades com população igual ou superior a 10 milhões de habitantes, número que avançará para 20 no ano 2010; é previsto também o aumento de 8 para $9 \%$ da contribuição dessas cidades para a população urbana. Por sua vez, o número de cidades com população inferior a 500 mil habitantes tende a aumentar, mas sua contribuição para a população urbana mundial cairá de $52 \%$ para $51 \%$.

Essas médias mundiais escondem importantes diferenças entre as distintas regiões: enquanto na África o percentual de urbanização da população não atinge 40\%, ainda que crescente ao longo do período 2005-2010, nos países da América Latina e Caribe, essa taxa é o dobro, isto é, atingirá 79,4\% no ano 2010. Trata-se de níveis de urbanização superiores aos apresentados pelos países das chamadas "regiōes mais desenvolvidas", cujo grau de urbanização da população também era crescente, e em 2010 atingirá 75\%. 
O Sudeste Asiático também experimenta crescimento da urbanização de sua população, que, entretanto, no ano 2010 atingirá apenas 48,5\%.

Todas as regiōes consideradas, exceto a África, experimentam taxas negativas de crescimento da população rural, mas todas vêm apresentando taxas positivas de aumento da população urbana. A elevada taxa de população rural só é significativa no grupo dos "países menos desenvolvidos", em que menos de $30 \%$ da população é urbana, ainda que venha crescendo à taxa média anual de 4,1\%, muito mais intensamente do que o 1,69\% de crescimento da população rural.

Considerando apenas os países da América do Sul, a taxa de urbanização da população passará de $81,8 \%$ em 2005 para $83,7 \%$ no ano 2010 . Enquanto a população rural experimenta declínio de $0,93 \%$ na taxa média anual, a população urbana apresenta crescimento médio anual de $1,7 \%$. A maior contribuição para esse crescimento virá das cidades com população entre 1 e 5 milhões de habitantes, que passarão de 29 para 35 no quinquênio considerado, o que significa aumento de $20 \%$ para $22 \%$ na população urbana deste subcontinente. As cidades com menos de 500 mil habitantes, apesar de aumentar em número, vão ter sua participação na população urbana diminuída, de 50\% para $49 \%$.

Entre os países mais populosos e/ou com os maiores PIBs regionais, há forte concentração de população vivendo em cidades com mais de 750 mil habitantes. As principais exceções são alguns países europeus de ocupação antiga, anterior à Revolução Industrial, como a Alemanha e a Suécia, que se caracterizam por maior dispersão de sua população. $\mathrm{Na}$ maioria dos casos, pode-se identificar uma relação positiva entre concentração da população em cidades de grande porte e importância econômica (em valor do PIB), o que sugere que haja forte concentração de oportunidades de emprego nas grandes cidades.

O "Demographic Yearbook 2007" da ONU utiliza o corte dos 750 mil habitantes para caracterizar a tendência à concentração da população em grandes cidades. Trata-se de um instrumento metodológico arbitrário, como seria qualquer recorte para permitir a caracterização da rede urbana em países tão distintos quanto são o Brasil, a Rússia, a Holanda ou a Nova Zelândia. Mesmo no caso brasileiro, um recorte pelo número de habitantes também seria arbitrário, uma vez que o extenso território nacional comporta uma grande diversidade de base produtiva e ocupação socioterritorial. Poderíamos ilustrar tal diversidade comparando o papel que uma cidade de 750 mil habitantes ocupa na rede urbana da região Sudeste com outra localizada na região Centro-Oeste: no primeiro caso, a cidade pode fazer parte de uma região metropolitana na condição de cidade periférica, enquanto que no segundo caso, certamente se trata de uma capital ou centro regional, com papel de articuladora do território regional ou, pelo menos, sub-regional.

Outra consideração a ser feita a propósito da arbitrariedade nos cortes pelo tamanho da população refere-se às mudanças ocorridas nas funções urbanas ao longo do tempo. Em estágios iniciais, o processo de urbanização esteve associado à expansão industrial e/ou reorganização da estrutura produtiva rural, liberando trabalhadores que se dirigiram às cidades. Etapas subsequentes, no entanto, têm diminuído a importância da industrialização, ainda que o processo de urbanização venha se acelerando, como indica o mencionado estudo demográfico da ONU. Nestas condições, eram as cidades com população entre 50 e 250 mil habitantes aquelas que apresentavam as funções intermediárias na rede urbana brasileira. Esse foi o entendimento dos pesquisadores que elaboraram o estudo "Sistema Urbano e Cidades Médias no Brasil” (Andrade \& Lodder, 1979) durante a década de 1970. A partir dos anos 1990, outros estudos passaram a utilizar o limiar de 100 mil habitantes para caracterizar o tamanho mínimo das cidades médias com aquelas funções urbanas intermediá- 
rias entre as metrópoles e as cidades pequenas. Podemos citar, nesse sentido, outro estudo do Instituto de Pesquisa Econômica Aplicada (IPEA), de 2001, que denominou cidades médias aqueles municípios com população entre 100 mil e 500 mil habitantes.

Neste estudo, pretendemos lançar um olhar sobre as "cidades médias", aqui definidas como aquelas com mais de 100 mil habitantes e que não sejam capitais estaduais. Essas últimas compõem o grupo de cidades com maior população e que, além disso, tornaram-se núcleo de áreas metropolitanas que incluem outros municípios vizinhos, formando uma urbanização estendida, fenômeno socioterritorial que não encontra equivalência nas fronteiras político-administrativas dos municípios que o compóem. As cidades médias, por sua vez, foram divididas entre as metropolitanas e não metropolitanas, sendo as primeiras situadas em regiōes metropolitanas nucleadas por capitais estaduais, o que as exclui da condição de centros regionais, articuladoras do território. Tal condição tende a ser exercida pelas "cidades médias não metropolitanas", sendo que o aumento do número destas cidades e do seu peso demográfico na população brasileira sugere sua relevância crescente na rede urbana brasileira.

A utilização do corte de 100 mil habitantes, apesar das críticas a que tal metodologia está sujeita, deve-se ao fato de que os resultados da pesquisa sobre a localização municipal dos empregos gerados ao longo do período considerado não se alteram em relação à metodologia da pesquisa REGIC/IBGE, que classifica os municípios brasileiros segundo seu grau de centralidade na rede urbana do País. Segundo o IBGE, existem 143 municípios com algum grau de centralidade (metrópoles, capitais regionais, centros sub-regionais e centros de zona). Desses, apenas 1, Ijuí (RS), não tinha população superior a 100 mil habitantes. Portanto, dos 252 municípios brasileiros que tinham população superior a 100 mil habitantes em 2007, 110 não tinham nenhum grau de centralidade: as 96 cidades médias metropolitanas e apenas 14 cidades médias não metropolitanas. Encontramos a mesma forte concentração da geração de empregos nas cidades com mais de 100 mil habitantes e no grupo de municípios com algum grau de centralidade, segundo o critério utilizado pela pesquisa REGIC/IBGE, como mostraremos nas tabelas 4 e 5 .

\section{Ordem Econômica do Século XXI Diminui Centralidade da Indústria no Processo de Urbanização}

A literatura contribuiu para disseminar uma imagem das cidades como lugares de libertação dos "grilhôes da terra". Essa imagem choca-se com a experiência atual dos residentes nas grandes cidades. $\mathrm{O}$ início do século XXI tem sido marcado pela intensificação da urbanização mundial, com tendência à concentração nas grandes cidades. A avassaladora urbanização mundial gerou imensas áreas urbanas, no sentido que lhe dá Françoise Choay (Lo Urbano, 2004), uma espécie de "cidade difusa" que tem empurrado os pobres para as franjas dessas áreas, onde o preço da terra é mais baixo e, assim, acessível à população de menor nível de renda. O baixo preço, no entanto, é a expressão da inadequação da infraestrutura, o que representa um custo para o deslocamento cotidiano da população que ali reside. Esse custo, que se manifesta em longos percursos que consomem horas e recursos dos pobres, acaba por resultar em novos grilhóes que aprisionam os pobres nessa atual urbanização concentrada.

Tal fenômeno suscita o questionamento sobre o porquê de a população seguir dirigindo-se até essas áreas polarizadas, onde ficará enredada neste novo tipo de "grilhão da terra”. A resposta mais provável associa-se à distribuição espacial das oportunidades de 
trabalho. Essas, por sua vez, estão relacionadas à dinâmica do capitalismo contemporâneo. Segundo a teoria urbana, o processo de globalização tem contribuído para modificar o modo como é estruturado o território, desde que as finanças sucederam a indústria como atividade dominante (Castells, 1999; Hall, 2004; Sassen, 2003; Harvey, 1992). O resultado tem sido o fortalecimento (e não o enfraquecimento) das metrópoles, que se tornaram pontos essenciais na economia contemporânea, tendo em vista a concentração de serviços especializados e de grande porte que permitiriam a conexão com outras metrópoles em um mundo globalizado. Trata-se daquilo que Milton Santos (1996) denominou "meio técnico" adequado à acumulação capitalista, disponível em grandes áreas urbanas.

Durante a fase em que o setor industrial comandou a dinâmica econômica, havia tendência à aglomeração espacial e à geração de cidades primazes; essas articulavam o território dos Estados nacionais em benefício do processo de industrialização, tornando as demais cidades e/ou regiōes dependentes das decisões emanadas desde aquele núcleo industrial e demográfico líder.

A partir do último quartel do século XX, contudo, a indústria vem perdendo centralidade na dinâmica econômica, e as cidades primazes perderam atratividade como lócus da indústria, tornando-se "economias de serviços".

De acordo com Benko (1996), na atual ordem globalizada, a estruturação do espaço assume uma nova característica, resultante da interação de três elementos principais: as indústrias de alta tecnologia, as atividades artesanais e as economias de serviços. As últimas estão presentes sobretudo nos espaços metropolitanos; as atividades artesanais (ou atividades produzidas em micro e pequenas empresas) apresentam padrão locacional mais disperso, ainda que tendam a se estabelecer em um número maior de cidades de porte médio.

Os serviços voltados para a produção (como serviços de controladoria, jurídicos ou financeiros) demandam um contingente de trabalhadores altamente especializados, somente passíveis de serem encontrados nas grandes metrópoles onde exista oferta desse tipo de força de trabalho, bem como infraestrutura logística adequada às tecnologias de informação e comunicação (Sassen, 2003).

De acordo com Harvey (1992), uma das manifestaçôes da nova ordem econômica internacional é o processo de "compressão tempo-espaço", para o qual foi fundamental o desenvolvimento de novas tecnologias, que permitem vencer as distâncias rapidamente e com baixo custo. Entretanto, nunca será atingida a neutralidade do espaço, e a aglomeração se mantém, ainda que por motivos distintos daqueles que levaram à concentração espacial durante a industrialização. A articulação do território por meio do espaço eletrônico está produzindo uma nova hierarquia urbana, no topo da qual, as cidades globais se mantêm, consolidando seu papel de comandantes da organização do território em escala global.

No Brasil, esses fenômenos também estão presentes e tendem a afirmar a cidade de São Paulo no topo da rede urbana do País, diminuindo a importância relativa da cidade do Rio de Janeiro, ainda que ambas consolidem seus papéis como importantes economias de serviços. No entanto, elas passaram a estar articuladas com a rede mundial de lugares de gestão do capital (as cidades globais, em seus diferentes níveis de importância hierárquica), e não apenas com o seu entorno físico-territorial, graças à expansão do espaço eletrônico.

A Indústria, por sua vez, tende a se deslocar para as cidades de porte médio, onde é possível evitar os custos das deseconomias de aglomeração (elevado preço da terra e do custo do trabalho, congestionamentos etc.), ainda que estejam disponíveis os atributos que lhes conferem economias externas (força de trabalho treinada e com menor organiza- 
ção sindical, terrenos baratos e acesso à infraestrutura logística). As grandes corporações empresariais operam com uma rede internacional de fornecedores (o que lhes permite grande liberdade na escolha locacional), mas a maior parte das empresas industriais, não; para estas (micro, pequenas e médias empresas), as relações cliente-fornecedor ainda se baseiam nos custos da distância, o que as leva a produzir aglomeração espacial. Nessas condiçōes, elas se constituem em importantes instrumentos de articulação espacial, o que as leva a cumprir papel significativo na rede urbana como organizadora do território.

Esse papel de articuladoras internas do território aumenta a relevância das cidades médias como agentes do processo de descentralização das políticas públicas (Santos, 2008; Affonso, 2004). Elas se transformam em centros regionais de serviços - dentre os quais se incluem os de formação de mão de obra para as atividades econômicas da região e para a gestão pública, tornada mais importante pela descentralização. Ademais, tendem a se constituir em núcleos de fornecimento de serviços de utilidade pública, para os quais é necessária escala de produção, a fim de que sejam economicamente viáveis.

Além disso, essa função se fortaleceu com a transformação de algumas infraestruturas sociais em direitos recepcionados pelas constituiçóes. No Brasil, o direito à saúde tornou-se um direito social, o que levou o poder público a organizar programas de acesso à saúde em bases territoriais visando a necessária universalização desse direito. Assim, foram definidos serviços de baixa, média e alta complexidade a serem disponibilizados em municípios conforme a sua capacidade de ofertar tais serviços.

O mesmo processo de regionalização ocorre com os serviços de acesso à Justiça e demais órgãos governamentais (Polícia Federal, Secretaria da Receita e Ministério Público, dentre outros), o que fortalece a função administrativa dessas cidades, intensificando seu papel de centro regional. Nessas condições, as cidades de médio porte tornaram-se elos ainda mais importantes na rede urbana, uma vez que passaram a cumprir mais funções na distribuição daqueles serviços para os seus residentes e os dos municípios vizinhos.

Nesse contexto, a expectativa é de que as cidades médias aumentem sua participação na população brasileira, tornando-se áreas de destino de fluxos migratórios em busca de oportunidades de emprego em cidades onde o custo de vida (particularmente o preço da terra urbana e do deslocamento casa-trabalho) seja inferior ao das metrópoles e que, além disso, haja melhores condiçôes de vida (com baixo percentual da população vivendo em situação de vulnerabilidade).

E o que diz a evidência empírica?

\section{O Que Dizem os Indicadores Socioeconômicos sobre a Concentração da População em Cidades de Médio e Grande Porte}

O Censo Demográfico de 2010 deverá atualizar as informações sobre população e condiçóes de vida, necessárias para avaliar o atual papel das cidades médias ao longo da primeira década do século XXI. Sem essa base de dados, este estudo lança mão de dois tipos de dados: i) as informações da publicação Indicadores Sociais Municipais (do IBGE, com base no Censo de 2000) disponíveis para a década de 1990 no que tange à remuneração média dos responsáveis pelos domicílios e o grau de precariedade de condiçóes de vida dos residentes nos domicílios brasileiros; e ii) as informações sobre a evolução na geração de empregos formais do CAGED/Ministério do Trabalho. Esses dados são utilizados para compor um retrato de algumas dimensões das condições vigentes nas cidades médias brasileiras no início da década e a situação atual, no final da década, por meio da avaliação 
do mercado de trabalho formal, utilizado como variável que expressa o processo de seu crescimento econômico afetando positivamente as condições de vida dos seus residentes.

\section{QUANTO MAIOR A POPULAÇÃO, MAIORES SÃO OS RENDIMENTOS E MENOR É O GRAU DE VULNERABILIDADE DOS SEUS RESIDENTES}

O Brasil conta com 5.565 municípios, dos quais apenas 4,53\% (252) têm população superior a 100 mil habitantes: 27 são capitais estaduais (incluindo o Distrito Federal), 96 são cidades médias metropolitanas e 129 são cidades médias não metropolitanas. A população das cidades com mais de 100 mil habitantes alcançou 53,61\% dos 183.987.291 habitantes do País, segundo a contagem populacional feita pelo IBGE no ano de 2007, apesar de essas cidades representarem menos de $5 \%$ do número de municípios.

A população brasileira está fortemente concentrada nas regiōes Sudeste $(42,32 \%)$ e Nordeste $(28,01 \%)$, restando cerca de $30 \%$ nas outras três macrorregióes (Norte, CentroOeste e Sul). As duas primeiras foram aquelas de ocupação mais antiga e consolidada, mas apresentando indicadores socioeconômicos muito distintos, o que se reflete na forma como se distribui a população entre as cidades mais e menos dinâmicas em termos populacionais. Enquanto no "rico" Sudeste as cidades médias e capitais estaduais contribuíam com 67,8\% da população regional, no "pobre” Nordeste, esse percentual foi de 39\%, menor do que nas outras macrorregiōes (aproximadamente $45 \%$ no Norte e Sul e de $53,1 \%$ no "emergente" Centro-Oeste).

No País, a taxa de urbanização da população tem se ampliado e vem se concentrando nas maiores cidades. Ainda que tal concentração suscite novos problemas que exijam elevados custos de infraestrutura para serem mitigados, existem razóes objetivas que alimentam os fluxos migratórios em direção às cidades médias e grandes. É o que sugerem os dados sobre rendimento médio e precariedade de condições de vida dos responsáveis pelos domicílios brasileiros.

Tabela 1 - Valor do rendimento médio dos responsáveis pelos domićlios particulares permanentes (em R \$) e grau de precariedade de condições de vida (em \%)*, segundo as classes de tamanho da população dos municípios - Brasil, 1991-2000

\begin{tabular}{|l|c|c|c|}
\hline \multirow{2}{*}{ Habitantes } & $\begin{array}{c}\text { Rendimento } \\
(\mathrm{R} \$)\end{array}$ & $\begin{array}{c}\text { Precariedade de } \\
\text { condiçôes de vida (\%) }\end{array}$ & $\begin{array}{c}\text { Precariedade de con- } \\
\text { diçóes de vida (\%) }\end{array}$ \\
\cline { 2 - 4 } & 2000 & 1991 & 2000 \\
\hline Brasil & 768,83 & 27,8 & 16,7 \\
\hline Até 5.000 & 424,08 & 49,5 & 32,4 \\
\hline De 5 a 10.000 & 409,66 & 52,1 & 34,7 \\
\hline De 10 a 20.000 & 416,32 & 53,1 & 35,5 \\
\hline De 20 a 50.000 & 479,55 & 46,4 & 29,9 \\
\hline De 50 a 100.000 & 612,80 & 32,0 & 18,4 \\
\hline De 100 a 500.000 & 810,47 & 16,2 & 8,0 \\
\hline Mais de 500.000 & $1.190,00$ & 7,8 & 4,0 \\
\hline
\end{tabular}

Fonte: IBGE. Censo demográfico 2000 e Indicadores Sociais Municipais, 2003.

${ }^{*}$ Grau de precariedade de condiçôes de vida é a proporção de domicílios particulares permanentes com saneamento não adequado, responsáveis com menos de quatro anos de estudo e rendimento mensal de até 2 salários mínimos. 
A distribuição dos municípios por classes de tamanho de sua população indica de modo inequívoco como o nível de rendimento está diretamente relacionado com o tamanho da população e com sua localização em macrorregiōes: quanto maior o tamanho da população do conjunto dos municípios brasileiros, maior se torna o rendimento médio auferido pelos responsáveis pelos domicílios particulares permanentes. Além disso, a localização na macrorregião Sudeste também garante maiores rendimentos e menor grau de vulnerabilidade de condições de vida.

$\mathrm{O}$ indicador de precariedade de condições de vida constitui uma síntese de três dados que, conjugados, revelam a incapacidade dos chefes de família de dispor das "capacidades básicas", de que fala Amartya Sen (2000), para usufruir de "liberdades substantivas", termo utilizado pelo autor para diferenciar das "liberdades formais", indo além destas e referindo-se a uma série de acessos necessários para tornar o homem livre de privações e pobreza, como boas condiçóes sanitárias, de saúde, educação e moradia. Nesse sentido, quanto maior for a proporção de chefes de família vivendo nesse nível de precariedade de condições de vida, pior será a perspectiva das localidades onde ela ocorre para experimentar um processo de desenvolvimento socioeconômico, o "desenvolvimento como liberdade", de acordo com Sen.

No Brasil, ao longo da década de 1990, houve um importante declínio do percentual de chefes de família vivendo em condições de precariedade: em todas as classes de tamanho dos municípios verificou-se melhoria desse indicador. No entanto, o diferencial por classes de tamanho foi mantido, isto é, as cidades com menos de 20 mil habitantes ainda apresentam aproximadamente $35 \%$ dos seus chefes de família vivendo nessa condição, percentual significativamente superior ao observado entre os municípios com mais de 100 mil habitantes, que está entre 4 e $8 \%$.

A tabela a seguir indica as disparidades no rendimento médio dos responsáveis pelos domicílios residentes nos municípios com mais de 100 mil habitantes. Pode-se verificar que é clara a relação entre a localização nas regiōes Sudeste e Sul e o maior nível de rendimento daqueles chefes de família. Ademais, os chefes que residem em capitais estaduais, em todas as macrorregiōes do País, auferem rendimento significativamente superior ao daqueles que residem em cidades médias, metropolitanas ou não metropolitanas. Aquelas localidades tendem a se manter, portanto, como destinos principais dos fluxos migratórios, tão característicos da intensa mobilidade da população brasileira.

Tabela 2 - Valor do rendimento médio dos responsáveis pelos domicílios particulares permanentes distribuídos entre cidades com população superior a 100 mil habitantes, divididas entre cidades médias (metropolitanas e não metropolitanas) e capitais estaduais (R\$)

\begin{tabular}{|l|c|c|c|}
\hline Cidades/Regiōes & $\begin{array}{c}\text { Cidades médias me- } \\
\text { tropolitanas (CMM) }\end{array}$ & $\begin{array}{c}\text { Cidades médias não } \\
\text { metropolitanas (CMN) }\end{array}$ & $\begin{array}{c}\text { Capitais } \\
\text { estaduais }\end{array}$ \\
\hline Centro-Oeste & 488,16 & 661,81 & $1.173,77$ \\
\hline Norte & 554,22 & 531,08 & 812,21 \\
\hline Nordeste & 533,68 & 476,57 & 860,02 \\
\hline Sudeste & 804,68 & 888,84 & $1.434,59$ \\
\hline Sul & 808,57 & 812,51 & $1.516,23$ \\
\hline Total capitais & - & - & $1.052,14$ \\
\hline Total CMM & 761,71 & - & - \\
\hline Total CMN & - & 767,17 & - \\
\hline
\end{tabular}

Fonte: IBGE. Indicadores Sociais Municipais (2003). 
Ao separar as cidades médias entre sua localização - metropolitana ou não metropolitana -, verifica-se uma diferença que merece ser destacada: o rendimento dos chefes de família residentes em cidades metropolitanas é superior ao daqueles que residem nas extrametropolitanas apenas nas macrorregiōes Norte e Nordeste, as mais pobres. Nas outras três, ocorre o inverso. Esse resultado nos leva a relacionar maior dinamismo econômico (identificado com níveis de rendimento mais elevados) à localização de cidades médias fora das regiōes metropolitanas. Pode-se sugerir, assim, que as cidades médias extrametropolitanas das regiōes mais dinâmicas têm constituído alternativa melhor para seus residentes do que aquelas localizadas em áreas metropolitanas. Nas regiōes Norte e Nordeste, contudo, é o dinamismo das metrópoles que extravasa em direção às cidades periféricas o fenômeno que predomina, resultando em rendimentos mais elevados dos residentes das cidades médias metropolitanas.

As desigualdades existentes entre as cidades segundo sua localização macrorregional também podem ser analisadas da perspectiva do grau de precariedade de condiçôes de vida entre os seus residentes. Ao contrário do observado com o rendimento, as desigualdades em termos de precariedade das condições de vida sugerem que as cidades localizadas fora de regiōes metropolitanas apresentam, em geral, situação pior que a observada nas áreas metropolitanas.

Tabela 3 - Proporção de domicílios particulares permanentes em situação de precariedade de condiçôes de vida em cidades com população superior a 100 mil habitantes, divididas entre cidades médias (metropolitanas e não metropolitanas) e capitais estaduais (\%), 1991-2000

\begin{tabular}{|l|c|c|c|c|c|c|}
\hline \multirow{2}{*}{ Cidades/regiōes } & \multicolumn{2}{|c|}{$\begin{array}{c}\text { Cidades médias me- } \\
\text { tropolitanas (CMM) }\end{array}$} & $\begin{array}{c}\text { Cidades médias } \\
\text { não metropolitanas } \\
\text { (CMN) }\end{array}$ & \multicolumn{2}{c|}{$\begin{array}{c}\text { Capitais } \\
\text { Estaduais }\end{array}$} \\
\cline { 2 - 7 } & 1991 & 2000 & 1991 & 2000 & 1991 & 2000 \\
\hline Centro-Oeste & 27,7 & 18,2 & 28,3 & 15,9 & 11,5 & 6,1 \\
\hline Norte & 17,1 & 10,2 & 40,3 & 25,5 & 19,3 & 10,7 \\
\hline Nordeste & 28,5 & 16,3 & 43,4 & 24,9 & 17,9 & 10,0 \\
\hline Sudeste & 11,7 & 4,6 & 11,2 & 4,6 & 4,9 & 1,2 \\
\hline Sul & 8,8 & 3,3 & 15,6 & 7,5 & 4,8 & 1,5 \\
\hline Total capitais & - & - & - & - & 13,9 & 7,4 \\
\hline Total CMM & 13,1 & 5,9 & - & - & - & - \\
\hline Total CMN & - & - & 21,7 & 11,3 & - & - \\
\hline
\end{tabular}

Fonte: IBGE. Indicadores Sociais Municipais, 2003.

Ao distribuir as cidades com mais de 100 mil habitantes entre as cinco macrorregiōes, verifica-se que o indicador de precariedade é muitíssimo mais elevado nas regiōes Norte, Centro-Oeste e Nordeste do que nas regiōes Sudeste e Sul. Nessas duas últimas, esse indicador é inferior a 5\%, enquanto nas outras três regióes ele é de aproximadamente $20 \%$. Cabe destacar: onde há maior dinamismo econômico, há baixo grau de chefes de família vivendo em situação de precariedade, ocorrendo o contrário onde é menor o dinamismo econômico. Nessas condições, o baixo índice de condições de vida tende a contribuir para uma espiral negativa observada nas regiões mais pobres. Nessas, apenas nas capitais estaduais o índice de precariedade é mais baixo; ainda assim, bem mais elevado do que o observado nas capitais estaduais do Sudeste e do Sul, mesmo se comparado com o das cidades médias dessas regiões. 
Observa-se, no entanto, que a divisão das cidades médias, estejam ou não localizadas em regiōes metropolitanas, indica, para todo o país, que as não metropolitanas apresentam indicadores piores - quase o dobro do apresentado pelas metropolitanas - de precariedade de condições de vida. Esse resultado deve estar associado mais com a inadequação da infraestrutura do que com o nível de rendimento da população, como visto na Tabela 2, e merece ser mais bem investigado, o que pretendemos fazer após a divulgação dos resultados do Censo de 2010.

Esse resultado é grave e contribui para a crise socioambiental das cidades, uma vez que, como se viu, as cidades médias não metropolitanas vêm experimentando crescimento demográfico e, conforme se verá, mais oportunidades de emprego nas regiões mais dinâmicas da economia brasileira.

\section{Quanto Maior a Cidade, Maior é a Geração de Empregos}

As cidades de maior porte demográfico tendem a apresentar economias mais fortes e diversificadas. A metodologia tradicional de análise da dinâmica econômica era feita por meio da avaliação do PIB municipal. Considerado como o valor de mercado da produção, o PIB pode superestimar o significado do dinamismo para a população local, como é o caso dos municípios que acolhem grandes investimentos cujo espaço econômico seja o global, como o da atividade de extração do petróleo. Tentando evitar esse problema, decidimos trabalhar com a criação líquida de empregos formais, que consideramos uma medida mais justa para avaliar a dinâmica econômica municipal que impacta positivamente a população local.

A Tabela 4 apresenta a distribuição espacial do saldo líquido dos empregos gerados segundo regióes geoeconômicas e classes de cidades. Trata-se de identificar as localidades onde o dinamismo na geração de empregos foi mais acentuado, permitindo avaliar o papel das cidades médias (e dos setores de atividades que mais contribuíram para o resultado encontrado, como se verá depois).

Ao observar a evolução na criação líquida de empregos ao longo da primeira década do século, verificamos que houve significativo aumento dos empregos, em particular entre 2003 e 2005, atingindo o auge em 2007, mas com declínio entre 2008 e 2009. Tal evolução está de acordo com a variação do crescimento do PIB brasileiro, que experimentou crescimento a partir de 2003, mas sentiu os efeitos da crise financeira mundial deflagrada em setembro de 2008.

Considerando a distribuição dos empregos entre as macrorregiōes brasileiras, verificamos que as cidades das regiōes Sudeste e Sul se destacam pelo número de empregos criados. Mas cabe realçar que o resultado mais significativo foi o avanço observado nas cidades da região Nordeste, sobretudo entre as capitais estaduais e as cidade médias não metropolitanas. Esse resultado sugere o impacto positivo das políticas de transferência de renda do governo federal na formalização e/ou criação de novos postos de trabalho na região mais pobre do País.

Ao analisar a distribuição dos municípios entre os dois grupos de cidades médias, observa-se que as metropolitanas ainda apresentaram estoque maior de empregos em relação às cidades médias não-metropolitanas. No entanto, isso deve mudar, pois as últimas vêm experimentando taxa de crescimento maior do que as metropolitanas. Portanto, a tendência mais geral foi de desenvolvimento desigual no avanço do emprego, com pior desempenho das cidades médias metropolitanas, o que deve ter acentuado sua condição 
de periferia (no sentido de áreas desprovidas de infraestrutura adequada e, por isso, com valor da terra menor e mais acessível aos pobres).

Tabela 4 - Distribuição espacial dos empregos (saldo entre admissões e demissões) segundo regiōes geoeconômicas e classes de cidades (capitais estaduais, cidades médias metropolitanas (CMM) e cidades médias não metropolitanas (CMN), 2000-2009

\begin{tabular}{|l|r|r|r|r|r|r|}
\hline $\begin{array}{l}\text { Regiöes/ clas- } \\
\text { ses de cidades }\end{array}$ & 2000 & 2003 & \multicolumn{1}{|c|}{2005} & \multicolumn{1}{c|}{2007} & \multicolumn{1}{c|}{2008} & 2009 \\
\hline BRASIL & 657.596 & 645.433 & 1.253 .981 & 1.617 .392 & 1.452 .204 & 995.110 \\
\hline Norte & 35.549 & 28.886 & 48.724 & 68.975 & 26.574 & 37.241 \\
\hline Capitais/BR & $3,31 \%$ & $2,10 \%$ & $2,95 \%$ & $2,17 \%$ & $1,81 \%$ & $3,29 \%$ \\
\hline CMM/Br & $0,14 \%$ & $0,21 \%$ & $0,10 \%$ & $0,15 \%$ & $0,03 \%$ & $0,07 \%$ \\
\hline CMN/BR & $0,20 \%$ & $0,61 \%$ & $0,23 \%$ & $0,24 \%$ & $0,39 \%$ & $0,43 \%$ \\
\hline Centro-Oeste & 47.839 & 58,003 & 55.864 & 93.995 & 106.351 & 70.138 \\
\hline Capitais/BR & $3,68 \%$ & $2,18 \%$ & $3,53 \%$ & $2,42 \%$ & $4,20 \%$ & $3,68 \%$ \\
\hline CMM/BR & $0,31 \%$ & $0,62 \%$ & $0,11 \%$ & $0,44 \%$ & $0,58 \%$ & $0,57 \%$ \\
\hline CMN/BR & $0,81 \%$ & $1,17 \%$ & $0,14 \%$ & $0,64 \%$ & $0,51 \%$ & $0,67 \%$ \\
\hline Nordeste & 102.549 & 84.104 & 197.014 & 204.310 & 203.617 & 227.376 \\
\hline Capitais/BR & $4,85 \%$ & $3,99 \%$ & $7,45 \%$ & $6,07 \%$ & $8,50 \%$ & $11,38 \%$ \\
\hline CMM/BR & $2,44 \%$ & $1,16 \%$ & $2,06 \%$ & $1,53 \%$ & $1,02 \%$ & $2,20 \%$ \\
\hline CMN/BR & $0,37 \%$ & $0,82 \%$ & $0,93 \%$ & $1,31 \%$ & $0,64 \%$ & $2,65 \%$ \\
\hline Sudeste & 359.945 & 318.708 & 790.111 & 949.797 & 840.299 & 476.031 \\
\hline Capitais/BR & $18,83 \%$ & $13,21 \%$ & $22,46 \%$ & $23,62 \%$ & $25,61 \%$ & $21,98 \%$ \\
\hline CMM/BR & $15,36 \%$ & $11,61 \%$ & $16,29 \%$ & $13,56 \%$ & $12,27 \%$ & $8,38 \%$ \\
\hline CMN/BR & $10,29 \%$ & $8,96 \%$ & $10,71 \%$ & $10,53 \%$ & $10,36 \%$ & $8,79 \%$ \\
\hline Sul & 111.714 & 155.732 & 162.268 & 300.315 & 275.363 & 184.324 \\
\hline Capitais/BR & $3,56 \%$ & $1,77 \%$ & $3,59 \%$ & $3,63 \%$ & $3,98 \%$ & $4,58 \%$ \\
\hline CMM/BR & $4,43 \%$ & $3,42 \%$ & $1,65 \%$ & $2,86 \%$ & $3,48 \%$ & $2,64 \%$ \\
\hline CMN/BR & $3,81 \%$ & $4,74 \%$ & $3,47 \%$ & $4,23 \%$ & $3,73 \%$ & $2,71 \%$ \\
\hline
\end{tabular}

Fonte: Elaboração própria com dados do CAGED/Ministério do Trabalho, 2000-2009.

Outro resultado que vale a pena ressaltar é a forte elevação da participação percentual das capitais estaduais em todas as macrorregiôes, destacando-se a elevação verificada nos estados das regiōes Nordeste e Sudeste. No Sudeste, esse índice atingiu mais de 20\% de todos os empregos gerados. Como se verá, esse resultado está associado ao aumento significativo do peso do setor de Serviços, combinado com a enorme perda nos empregos na Indústria de Transformação.

Além disso, outro resultado importante a ser destacado é que houve declínio nas participações dos dois grupos de cidades médias na região Sudeste em relação ao País, mas foi muito maior entre as cidades médias metropolitanas. Portanto, o dinamismo recente na geração de empregos na região mais rica do País está se manifestando sob a forma de distribuição de empregos mais favorável às cidades médias fora das regiôes metropolitanas, o que é positivo e indicativo de desconcentração (ainda que concentrada regionalmente) da expansão econômica.

Os municípios com mais de 100 mil habitantes também podem ser distribuídos segundo sua posição hierárquica na rede urbana brasileira, conforme pesquisa do IBGE 
(REGIC/IBGE, 2008), já mencionada anteriormente. Na classificação dessa pesquisa, os municípios foram distribuídos em quatro níveis de centralidade: 12 são metrópoles, 70 compõem o grupo das "capitais regionais" (incluindo Ijuí, no Rio Grande do Sul), 56 são capitais sub-regionais e nove são "centros de zona". Os demais municípios foram considerados "centros locais". Estes últimos não passam de cidades isoladas, sem apresentar grau de centralidade em relação a outras cidades.

As capitais estaduais estão incluídas entre os níveis hierárquicos mais elevados, salvo capitais dos menores estados da região Norte; duas foram consideradas "centros locais".

As cidades médias não metropolitanas estão distribuídas entre os outros três níveis hierárquicos, exceto 14 delas, que foram classificadas como "centros locais". Assim, das 129 cidades, 115 têm graus de centralidade que variam de "capital regional" (casos de Campinas, Uberlândia, Londrina e Campos dos Goytacazes), "capital sub-regional" (casos de Anápolis, Itajaí, Macaé e Sinop) a "centros de zona” (casos de Porto Seguro, Jundiaí e Codó).

As cidades médias metropolitanas estão incluídas entre os "centros locais", uma vez que se situam como área de influência do núcleo da região metropolitana a que pertencem.

A tabela a seguir resume a evolução dos empregos nos municípios que compõem esses quatro níveis hierárquicos de cidades.

Tabela 5 - Distribuição espacial dos empregos (saldo entre admissões e demissões) dos municípios com população superior a 100 mil habitantes, segundo posição hierárquica na rede urbana brasileira, 2000-2009 (\%)

\begin{tabular}{|l|c|c|c|c|c|c|}
\hline $\begin{array}{l}\text { Posição na } \\
\text { rede urbana }\end{array}$ & 2000 & 2003 & 2005 & 2007 & 2008 & 2009 \\
\hline Brasil & 657.596 & 645.433 & 1.253 .981 & 1.617 .392 & 1.452 .204 & 995.110 \\
\hline Metrópoles (12) & $30,69 \%$ & $20,68 \%$ & $35,03 \%$ & $33,51 \%$ & $38,31 \%$ & $38,30 \%$ \\
\hline $\begin{array}{l}\text { Capitais } \\
\text { regionais (70) }\end{array}$ & $13,12 \%$ & $13,71 \%$ & $17,45 \%$ & $15,73 \%$ & $18,54 \%$ & $16,88 \%$ \\
\hline $\begin{array}{l}\text { Centros sub- } \\
\text { regionais (56) }\end{array}$ & $4,23 \%$ & $6,67 \%$ & $2,66 \%$ & $4,24 \%$ & $2,88 \%$ & $4,27 \%$ \\
\hline $\begin{array}{l}\text { Centros de } \\
\text { zona (9) }\end{array}$ & $1,05 \%$ & $0,63 \%$ & $0,97 \%$ & $1,31 \%$ & $1,02 \%$ & $0,63 \%$ \\
\hline $\begin{array}{l}\text { Centros locais } \\
(106)\end{array}$ & $19,51 \%$ & $14,24 \%$ & $17,93 \%$ & $16,24 \%$ & $15,31 \%$ & $11,91 \%$ \\
\hline
\end{tabular}

Fonte: Elaboração própria com base nos dados do CAGED/Ministério do Trabalho, 2000/2009.

Essa redistribuição dos municípios com mais de 100 mil habitantes segundo sua posição hierárquica na rede de cidades brasileiras mostra de forma contundente que houve concentração dos empregos nas cidades que estão no topo da rede urbana. Os municípios com mais de 100 mil habitantes (mais Ijuí) eram responsáveis por 68,6\% de todos os empregos gerados em 2000, percentual que se elevou para 71,99\% em 2009.

As metrópoles participavam com 30,69\% do saldo líquido dos empregos gerados no ano de 2000, proporção que evoluiu para 38,30\% em 2009, maior que sua participação na população brasileira em 2007, da ordem de 33,73\%. O segundo nível hierárquico, o 
das capitais regionais, também experimentou crescimento, de $13,18 \%$ para $16,88 \%$, no mesmo período, sendo, no entanto, menor do que a participação de 18,98\% destes municípios na população brasileira. Os centros locais, por outro lado, viram sua participação percentual nos empregos criados no País declinar de 19,51\% para 11,91\% ao longo da primeira década do século XXI, mas, ainda assim, é maior que o peso demográfico deste grupo de municípios na população do País, equivalente a 11,56\%.

Portanto, os municípios que foram os principais beneficiários em termos de geração líquida de empregos no período considerado foram as capitais estaduais e um grupo de cidades de elevado porte demográfico, constituído daquilo que neste estudo estamos chamando de "cidades medias não metropolitanas". As cidades médias metropolitanas, além das 14 não metropolitanas, que estão incluídas entre os 106 municípios considerados "centros locais" (sem apresentar nível de centralidade na rede urbana), foram os principais perdedores dentre os 252 municípios com mais de 100 mil habitantes, ainda que tenham uma participação de destaque, em termos absolutos, nos empregos gerados ao longo da década 2000/2009.

Identificada a tendência à concentração dos empregos nas cidades de maior porte demográfico, resta verificar se ocorreu redistribuição setorial desses empregos ao longo da década 2000/2009.

Tabela 6 - Evolução da participação setorial dos empregos no Brasil, 2000-2009 (\%)

\begin{tabular}{|l|c|c|c|c|c|c|}
\hline Atividades & 2000 & 2003 & 2005 & 2007 & 2008 & 2009 \\
\hline Indústria de Transformação & 29,32 & 19,95 & 14,16 & 24,40 & 12,30 & 10,94 \\
\hline Serviços & 43,18 & 40,33 & 47,58 & 36,3 & 44,64 & 50,26 \\
\hline Comércio & 26,68 & 35,00 & 31,01 & 25,05 & 26,32 & 29,86 \\
\hline Extração Mineral & 0,56 & 1,02 & 0,76 & 0,60 & 0,60 & 0,20 \\
\hline Administração Pública & 0,48 & 1,52 & 1,72 & 0,94 & 0,71 & 1,82 \\
\hline
\end{tabular}

Fonte: Elaboração própria com base nos dados do CAGED/Ministério do Trabalho, 2000/2009.

A Indústria de Transformação foi o setor que levou ao processo de polarização espacial nas metrópoles, mas vem perdendo centralidade na geração dos novos empregos. Ainda assim, cabe destacar que no ano em que o crescimento dos empregos foi mais significativo (2007), esse setor cresceu fortemente, ainda que sem voltar a atingir sua contribuição no emprego no País no ano 2000. Em seguida, voltou a declinar, em um processo de esvaziamento de sua importância setorial que parece sem volta. Cabe salientar que os resultados encontrados permitem alimentar a expectativa de que uma expansão sustentada no tempo deverá se traduzir em mais oportunidades de emprego industrial, o que se refletirá na crescente relevância das cidades medias não metropolitanas.

As atividades que experimentaram maior crescimento foram Serviços, beneficiadas pela atual dinâmica capitalista, com a produção de inovações em produtos e processos que as grandes aglomerações estimulam. Nessas condições, observa-se a sustentação do papel das grandes cidades, que deixam de ser caracterizadas como metrópoles industriais e tornam-se "economias de serviços", como foram caracterizadas por Benko (1996).

A análise desse desempenho setorial das atividades econômicas apresenta peculiaridades que devem ser destacadas ao se considerarem os três grupos de cidades deste estudo. Vamos considerar inicialmente o da Indústria de Transformação, setor que a teoria 
sustenta que tenderia a mudar sua localização, evitando as áreas metropolitanas ou, pelo menos, o núcleo dessas áreas, dirigindo-se às cidades médias.

Tabela 7 - Distribuição dos empregos no setor Indústria de Transformação nas capitais, cidades médias metropolitanas (CMM) e cidades médias não metropolitanas (CNM), 2000-2009

\begin{tabular}{|c|c|c|c|c|c|c|c|}
\hline \multicolumn{2}{|c|}{ Localização } & 2000 & 2003 & 2005 & 2007 & 2008 & 2009 \\
\hline \multirow{2}{*}{ Ind/total $*^{*}$} & 29,32 & 19,95 & 14,16 & 24,40 & 12,30 & 10,94 \\
\hline \multirow{2}{*}{ Brasil } & $\mathrm{n}^{\circ}$ & 192.863 & 128.791 & 177.548 & 394.584 & 178.675 & 108.865 \\
\cline { 2 - 8 } & $\%$ & 100 & 67 & 92 & 205 & 93 & 6 \\
\hline \multirow{2}{*}{ Capitais } & $\mathrm{n}^{\circ}$ & 35.489 & $3.830^{* *}$ & 49.180 & 69.828 & 48.549 & -585 \\
\cline { 2 - 8 } & $\%$ & 100 & $10,79 * *$ & 138,50 & 196,76 & 136,80 & $-1,65$ \\
\hline \multirow{2}{*}{$\mathrm{CMM}$} & $\mathrm{n}^{\circ}$ & 42.625 & 15.648 & 43.695 & 82.454 & 39.136 & -22.737 \\
\cline { 2 - 8 } & $\%$ & 100 & 36,71 & 102,51 & 193,44 & 91,81 & $-53,34$ \\
\hline \multirow{2}{*}{ CMN } & $\mathrm{n}^{\circ}$ & 45.039 & 23.875 & 35.531 & 94.843 & 27.800 & -2.289 \\
\cline { 2 - 8 } & $\%$ & 100 & 53,01 & 78,89 & 210,58 & 61,72 & $-5,08$ \\
\hline
\end{tabular}

Fonte: Elaboração própria com base nos dados do CAGED/Ministério do Trabalho, 2000/2009.

* Em relação ao total do saldo líquido dos empregos criados no país.

** Estes dados foram revisados, mas não encontramos erros em relação às informações do CAGED.

Conforme os dados sugerem, há base empírica para sustentar aquela tese, pois foi nas capitais estaduais, núcleos das principais metrópoles brasileiras, que o setor perdeu mais participação percentual na geração de empregos. A Indústria de Transformação também perdeu importância nas cidades médias, mas bem menos entre as não metropolitanas, resultado também consistente com a tese acima aludida.

Os Serviços se firmaram como principal fonte de empregos e se destacaram principalmente entre as capitais estaduais. Quando o foco são as cidades médias, os dados indicam que elas também ampliaram sua dependência dessa atividade, mas, também neste setor, as não metropolitanas vivenciaram crescimento mais significativo, até ultrapassando, em termos absolutos, as metropolitanas no último ano da série considerada (2009).

Tabela 8 - Distribuição dos empregos no setor Serviços nas capitais, cidades médias metropolitanas (CMM) e cidades médias não metropolitanas (CNM) 2000-2009

\begin{tabular}{|l|c|c|c|c|c|c|c|}
\hline \multicolumn{2}{|c|}{ Localização } & 2000 & 2003 & 2005 & 2007 & 2008 & 2009 \\
\hline \multirow{2}{*}{ Serviços/total \%* } & 43,18 & 40,33 & 47,58 & 36,3 & 44,64 & 50,26 \\
\hline \multirow{2}{*}{ Brasil } & $\mathrm{n}^{\circ}$ & 283.928 & 260.285 & 569.705 & 587.103 & 648.259 & 500.177 \\
\cline { 2 - 8 } & $\%$ & 100 & 92 & 201 & 207 & 228 & 176 \\
\hline \multirow{2}{*}{ Capitais } & $\mathrm{n}^{\mathrm{o}}$ & 120.034 & 108.416 & 268.489 & 302.719 & 348.041 & 235.921 \\
\cline { 2 - 9 } & $\%$ & 100 & 90,32 & 223,68 & 252,19 & 289,95 & 196,55 \\
\hline \multirow{2}{*}{$\mathrm{CMM}$} & $\mathrm{n}^{\mathrm{o}}$ & 63.997 & 53.728 & 114.921 & 113.281 & 112.546 & 83.532 \\
\cline { 2 - 8 } & $\%$ & 100 & 83,95 & 179,57 & 177,01 & 175,86 & 130,52 \\
\hline \multirow{2}{*}{ CMN } & $\mathrm{n}^{\mathrm{o}}$ & 42.194 & 41.833 & 79.254 & 80.606 & 90.518 & 86.703 \\
\cline { 2 - 8 } & $\%$ & 100 & 99,14 & 187,83 & 191,04 & 214,53 & 205,49 \\
\hline
\end{tabular}

Fonte: Elaboração própria com base nos dados do CAGED/Ministério do Trabalho, 2000/2009.

* Em relação ao total do saldo líquido dos empregos criados no ano. 
Concluindo a análise da distribuição espacial e setorial do saldo líquido dos empregos gerados, verificamos que os dados sugerem a manutenção da polarização espacial do mercado de trabalho. Nas macrorregiões mais dinâmicas, Sudeste e Sul, se observa desconcentração em direção às cidades médias, enquanto nas outras regiōes as oportunidades de trabalho estão mais concentradas ainda nas suas regiōes metropolitanas. $\mathrm{O}$ maior ativismo das políticas governamentais pode estimular a desconcentração dessas oportunidades de trabalho, mas sem alterar de forma significativa o maior peso das grandes metrópoles.

\section{CONCLUSÕES}

$\mathrm{O}$ processo de fortalecimento da polarização espacial tende a transformar as maiores cidades em lócus da crise social. A questão urbana não é somente prover moradia e serviços sociais. É preciso providenciar respostas para pelo menos cinco novos desafios: trabalho e renda, segurança, integração sociocultural, sustentabilidade e governança.

Neste estudo, demos destaque à dimensão "geração de emprego e renda", por acreditarmos que esta seja a responsável pela pressão demográfica que leva ao surgimento das demais dimensões da "questão urbana".

A geração de emprego e renda, por sua vez, está associada às mudanças observadas na dinâmica capitalista, que, nas últimas duas décadas do século XX, vinham se manifestando como a passagem do "fordismo para a acumulação flexível", segundo caracterização de David Harvey (1992). Isso significa implicações que se expressam em menor comprometimento das atividades produtivas com um determinado território, bem como com menor importância da Indústria na geração do PIB e nos empregos. Os Serviços tornam-se o centro de maior dinamismo econômico, destacando-se, dentre eles, os serviços financeiros.

A “acumulação flexível”, no entanto, deveria ter promovido maior desconcentração produtiva do que a experimentada na última década. Depois de sofrerem com processos de desindustrialização ao longo da década de 1980, as metrópoles voltaram a atrair mais população, em um reflexo evidente da expansão das oportunidades de emprego nas atividades de Serviços. Esta, aliás, foi a expectativa alimentada com a abordagem de Milton Santos (1996), para quem as áreas metropolitanas oferecem o meio técnico adequado à atual dinâmica capitalista.

Os dados sobre a espacialidade dos empregos criados ao longo do período 2000/2009 no Brasil indicam que as cidades de maior porte demográfico foram as que se destacaram nesse quesito. Em todas as macrorregiōes, as capitais estaduais, quase todas cidades classificadas como "metrópoles" pelo IBGE (REGIC/2008), foram as que experimentaram maior taxa de crescimento no emprego, o que explica seu peso demográfico em expansão.

No entanto, ao considerarmos os outros níveis de centralidade na hierarquia urbana, aumenta o peso das cidades médias, principalmente daquelas localizadas nas regiōes mais dinâmicas, Sudeste, principalmente, e Sul. Trata-se de cidades médias não metropolitanas, que vêm se transformando em núcleos de áreas regionais. Nessas regiōes, a rede urbana torna-se mais capilarizada e dependente dessas cidades médias não metropolitanas, ainda que se reconheça que as metrópoles seguem polarizando as maiores oportunidades de emprego. 
Angela Moulin S. Penalva

Santos é professora associada da UERJ; economista; pesquisadora do CNPq e do Programa ProCiência, da FAPER/UERJ. E-mail: angela penalva@terra.com.br

Artigo recebido em setembro de 2010 e aprovado para publicação em fevereiro de 2011.
Nas outras macrorregiōes, esse processo parece estar em seus primórdios, especialmente na regiāo Nordeste, onde vem apresentando indícios de fortalecimento.

Os resultados apontam para o fortalecimento das cidades médias, especialmente das não metropolitanas, na rede urbana brasileira. O Censo Demográfico 2010 permitirá avançar na avaliação de seu desempenho demográfico, bem como das condiçōes de vida dos seus residentes.

As maiores aglomerações urbanas tornaram-se lócus de forte crise socioambiental, intensificando sua geração de empregos, mas à custa de crescente deterioração das condições de vida na metrópole. A vida nessas cidades vem gerando novos "grilhões da terra", que parecem não intimidar os investidores que usam o solo urbano (produto social) para criar riqueza privada.

Quando as principais áreas metropolitanas brasileiras foram se consolidando, prevalecia uma abordagem de política pública "desenvolvimentista", que associava aumento da urbanização e da industrialização como fenômenos a evocar a superação do subdesenvolvimento. Ao longo da década de 1980, aquela abordagem foi sendo superada, e a agenda da "questão urbana" emergiu, resultando na criação de novos instrumentos jurídicos e urbanísticos que visavam o controle público do processo de expansão urbana.

É preciso utilizar tais instrumentos para evitar que as cidades médias reproduzam os mesmos desafios que hoje dificultam a vida dos residentes das metrópoles. Cabe agora torcer para que o Censo Demográfico não traga evidências de que esse processo já esteja em curso.

\section{REFERÊNCIAS BIBLIOGRÁFICAS}

AFFONSO, J. R. Brasil, um caso à parte. In: XVI Regional Seminar of Fiscal Policy, Santiago do Chile, CEPAL/ILPES. In: <www.federativo.gov.br>, janeiro, 2004.

ANDRADE, T. A.; LODDER, C. Sistema Urbano e Cidades Médias no Brasil. Rio de Janeiro: IPEA/INPES, 1979.

ANDRADE, T. A.; SERRA, R. V. (Org.). Cidades Médias Brasileiras. Rio de Janeiro: IPEA, 2001.

BENKO, G. Economia, Espaço e Globalização na aurora do século XXI. São Paulo: Hucitec, 1996.

CASTELLS, M. A sociedade em rede. São Paulo: Paz e Terra, 1999.

CHOAY, F. El reino de lo urbano y la muerte de la ciudad. In: RAMOS, A. R. (Ed) Lo Urbano en 20 autores contemporáneos. Barcelona: Ediciones UPC, 1994.

HALL, P. Megaciudades, ciudades mundiales y ciudades globales. In: RAMOS, A. R. (Ed.) Lo Urbano en 20 autores contemporáneos. Barcelona: Ediciones UPC, 2004.

HARVEY, D. Condição pós-moderna. São Paulo: Loyola, 1992.

IBGE. Indicadores Sociais Municipais. Brasília, IBGE, 2003.

ORGANIZAÇÃO DAS NAÇÕES UNIDAS. Demographic Yearbook 2007. Disponível em: <http://www.unstats.un.org/unsd/Demographic/Products/socind/population.htm>. Acesso em 31 de julho de 2009.

SANTOS, A. M. S. P. Município, descentralização e território. Rio de Janeiro: Forense, 2008.

SANTOS, M. A urbanização brasileira. São Paulo: Hucitec, 1996.

SASSEN, S. Los espectros de la globalización. Buenos Aires: Fondo de Cultura Económica, 2003. 


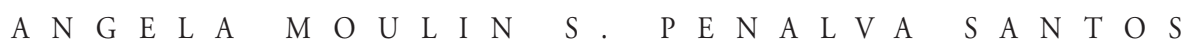

SEN, A. Desenvolvimento como liberdade. São Paulo: Companhia das Letras, 2000.

A B S T R A C T The aim of this paper is to discuss the role of cities with more than 100,000 inhabitants in the Brazilian urban network in the first decade of this century. Our premise is that in the context of loss of centrality of the Industry there is a tendency of urbanization with concentration of population in a few cities. In this process, besides the metropolis affirmation, increases the relevance of a group of medium-size cities that became regional centers and articulate the territory. Whe call "medium size non-metropolitan cities" the cities with more than 100,000 inhabitants that are not state capitals and are not inside metropolitan areas. The increasing urbanization, the spatial polarization and the employment growth in those cities make necessary public policies to avoid the effects of urban crisis that the metropolitan areas have already experienced.

K E Y W O R D S Medium size cities; urbanization; spatial polarization; employment generation; urban network. 